\title{
Nader Nasiri-Moghaddam, La Révolution constitutionnelle à Tabriz à travers les Archives diplomatiques françaises (1906 - 1909)
}

Philippe Rochard

\author{
(2) OpenEdition \\ Journals \\ Édition électronique \\ URL : http://journals.openedition.org/abstractairanica/47476 \\ DOI : 10.4000/abstractairanica.47476 \\ ISBN : 1961-960X \\ ISSN : 1961-960X \\ Éditeur : \\ CNRS (UMR 7528 Mondes iraniens et indiens), Éditions de l'IFRI
}

\section{Référence électronique}

Philippe Rochard, «Nader Nasiri-Moghaddam, La Révolution constitutionnelle à Tabriz à travers les Archives diplomatiques françaises (1906 - 1909) », Abstracta Iranica [En ligne], Volume 37-38-39 | 2018 document 2, mis en ligne le 30 décembre 2018, consulté le 28 septembre 2020. URL : http:// journals.openedition.org/abstractairanica/47476; DOI : https://doi.org/10.4000/abstractairanica 47476

Ce document a été généré automatiquement le 28 septembre 2020.

Tous droits réservés 


\title{
Nader Nasiri-Moghaddam, La Révolution constitutionnelle à Tabriz à travers les Archives diplomatiques françaises (1906 - 1909)
}

\author{
Philippe Rochard
}

\section{RÉFÉRENCE}

Nader Nasiri-Moghaddam, La Révolution constitutionnelle à Tabriz à travers les Archives diplomatiques françaises (1906 - 1909). Saint Denis : Connaissances et Savoirs, 2016, 606p.

1 Cet ouvrage riche, précis - fruit d'une recherche de longue haleine et édité sous les auspices du Groupe d'Etudes Orientales, Slaves et Néo-helléniques de l'Université de Strasbourg (GEO) - offre à tous les chercheurs travaillant sur cette période mouvementée et cette ville une source d'informations et de réflexions originales et renouvelées. L'auteur nous révèle pour la première fois le contenu de l'ensemble des dépêches diplomatiques du Consulat de France à Tabriz dûment annoté, et répertorié dans un tableau chronologique. Il offre aussi un point très complet sur : l'ensemble des personnages évoqués, l'évolution de la situation politique à Tabriz de 1896 à 1909, une mise en contexte avec les évènements de Téhéran, un état de la recherche détaillé de toutes les sources disponibles issues directement des pro- et des anticonstitutionnalistes de l'époque, de la presse ou encore des observateurs étrangers (ottomans, russes, britanniques et français). L'auteur nous révèle enfin l'action et l'œuvre d'un homme : le consul de France Alphonse Nicolas (1864-1939). Né à Rasht au sein d'une famille de diplomates français puis, ses études terminées, nommé à son tour à Tabriz, cet homme - amateur et traducteur de littérature classique persane, lisant et parlant couramment le persan, l'anglais et le russe - se distingue à la fois par un souci de précision dans l'analyse des évènements clairement remarquée par la chancellerie française et par une étude approfondie de la culture persane et des transformations 
politiques et religieuses qu'elle est en train de vivre à cette époque (contraint par son devoir de réserve, il signe aussi des articles sur la question persane dans la presse, sous pseudonyme). Progressivement acquis aux idées du bâbisme, mais critique vis-à-vis du Bahaïsme, Nicolas va s'employer à traduire et diffuser en France l'œuvre entière et la doctrine de Seyyed 'Ali Mohammad Shirāzi dit le Bāb. Il s'éteint le 28 février 1939 quelques semaines à peine après qu'Edith Sanderson, qu'on ne présente pas, l'eût interviewé. Bref, un ouvrage indispensable pour l'étude de la période.

\section{AUTEURS}

\section{PHILIPPE ROCHARD}

Université de Strasbourg 